\title{
Distúrbios reprodutivos em cabras leiteiras e impactos potenciais nos sistemas de produção
}

Ana Lucia Rosa e Silva Maia(a)", Maria Emília Franco Oliveira(b) , Joanna Maria Gonçalves Souza-Fabjan ${ }^{(c)}$, Mário Felipe Alvarez Balaro $^{(\mathrm{d})}$, Felipe Zandonadi Brandão(e), Jeferson Ferreira da Fonseca ${ }^{(\mathrm{f})}$

\footnotetext{
[a] Doutoranda em Clínica e Reprodução Animal, Universidade Federal Fluminense (UFF), Niterói, RJ, Brasil

${ }^{[b]}$ Doutora em Medicina Veterinária (Reprodução Animal), Professora colaboradora do Programa de Pós-Graduação em Medicina Veterinária, Faculdade de Ciências Agrárias e Veterinárias, Universidade Estadual Paulista (UNESP), Jaboticabal SP, Brasil

[c] Doutora em Ciências Veterinárias, Professora da Universidade do Grande Rio (Unigranrio), Duque de Caxias, RJ, Brasil; Pós-doutoranda da Universidade Federal Fluminense (UFF), Niterói, RJ, Brasil

${ }^{[d]}$ Doutor em Clínica e Reprodução Animal, Universidade Federal Fluminense (UFF), Niterói, RJ, Brasil

[e] Professor Associado da Faculdade de Veterinária, Universidade Federal Fluminense (UFF), Niterói, RJ, Brasil

${ }^{[f]}$ Pesquisador da Embrapa Caprinos e Ovinos, Núcleo Regional Sudeste, Coronel Pacheco, MG, Brasil
}

*Autor correspondente

e-mail: maia.analucia@gmail.com

\section{Introdução}

Múltiplos fatores podem impactar positiva ou negativamente a eficiência produtiva em rebanhos de caprinos leiteiros. Todavia, considerando que as condições de manejo geral, incluindo sanitário e nutricional, estejam adequadas, a eficiência reprodutiva é que determina em última análise a eficiência de exploração do rebanho (Fonseca et al., 2010).

A cabra, particularmente, desenvolve e manifesta alguns distúrbios que podem ser evidentes ou silenciosos de acordo com o seu comportamento. De forma geral, estes distúrbios estão associados a falhas reprodutivas que elevam o período de serviço e o intervalo de partos, podendo comprometer temporária (subfertilidade) ou permanentemente (infertilidade) a função reprodutiva das cabras. Identificar a ocorrência destes distúrbios, alternativas terapêuticas e o potencial de recuperação das fêmeas é, portanto, fundamental.

As anotações de ocorrências reprodutivas associadas à avaliação ultrassonográfica periódica são tópicos essenciais para a caracterização casuística dos principais distúrbios reprodutivos nas cabras. Com base nestas informações, tornase possível identificar animais com distúrbios predominantemente associados a condições endócrinas, fisiológicas, comportamentais, e o grau de acometimento do sistema reprodutivo. 
Sumarizar os principais distúrbios reprodutivos e seus potenciais impactos sobre a eficiência produtiva de caprinos leiteiros é o objetivo desta revisão.

\section{Ciclo estral na cabra}

Dependendo da latitude em que se encontram, cabras e ovelhas apresentam estacionalidade reprodutiva. Desta forma, em regiões de elevada latitude, o estímulo para a manifestação e/ ou intensificação dos fenômenos reprodutivos é o decréscimo no número de horas de luz por dia (fotoperíodo). De forma geral, o esplendor reprodutivo ocorre no outono. Ressalta-se que a atividade reprodutiva nos machos também é afetada pelo fotoperíodo (Fonseca et al., 2007) (Figura 1).

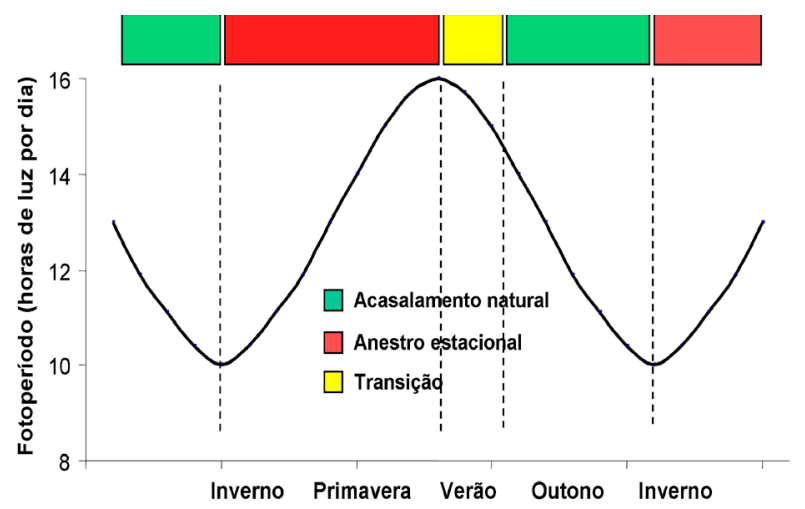

Nota: Adaptado de Fonseca et al. (2009)

Figura 1 - Variação anual no fotoperíodo, estações do ano e efeito sobre a reprodução de caprinos e ovinos.

Variações na latitude e sua relação com as estações geram o menor (solstício de inverno) e maior (solstício de verão) dia do ano, bem como dias onde a duração da noite iguala-se à duração do dia (quinócio) (Figura 2). À medida que se aproxima da linha do Equador, a estacionalidade reprodutiva é diminuída ou findada, pois praticamente os dias são iguais às noites ao longo de todo o ano. Desta forma, em áreas subequatoriais, como, por exemplo, no Norte brasileiro, desde que haja aporte nutricional em quantidade e qualidade suficientes, cabras manifestarão estro durante todo o ano. A ciclicidade também é fortemente influenciada pelo fator raça. Por exemplo, caprinos (Canindé, Moxotó, SRD) de raças nativas brasileiras apresentam atividade reprodutiva durante todo o ano, mesmo em áreas próximas aos trópicos, o que não acontece com caprinos de raças leiteiras especializadas (Saanen, Alpina e Toggenburg) (Fonseca et al., 2007).

Balaro (2016), avaliou a estacionalidade reprodutiva em 40 cabras da raça Saanen de diferentes ordens de parto (nulípara, primípara e plurípara), mantidas em sistema intensivo e fotoperíodo tropical (11-13 horas de luz por dia), durante o período de um ano no Rio de Janeiro, região Sudeste do Brasil (latitude 22 52' 30"sul). Quinzenalmente, o sangue de cada animal foi colhido para análise das concentrações séricas de progesterona e identificação do estado cíclico. As cabras nulíparas apresentaram a estação reprodutiva no período do inverno enquanto que as cabras primíparas e pluríparas mantiveramse cíclicas no outono e inverno. Independente da ordem de parto, todos os animais apresentaram anestro estacional marcado na primavera.

O ciclo estral na cabra tem uma duração média de 21 dias, apresentando uma fase luteal de 17 dias e uma fase folicular de quatro dias. Durante o ciclo estral, duas a quatro ondas (Ginther e Kot, 1994; Deshpande et al., 1999; Evans, 2003) foliculares podem estar presentes, mas apenas da última onda folicular deriva o folículo ovulatório que alcança maturação final e ovulação em ambiente hormonal com preponderância de atividade estrogênica. A ovulação pode ser única ou múltipla e ocorre predominantemente no final do estro ou logo após o seu final (Gordon, 1997; Fonseca et al., 2012). Após a ovulação, formam-se os corpos lúteos que aumentam de diâmetro e iniciam a atividade progesterônica que será encerrada, a menos que ocorra o reconhecimento e manutenção da gestação. Embora a prolificidade, em consequência do número de ovulações, seja considerada maior em caprinos, esta variação parece estar mais vinculada ao fator raça, tendo-se raças caprinas com maior ou menor prolificidade. Não obstante, a categoria também pode estar relacionada, visto que fêmeas nulíparas apresentam menor prolificidade do que fêmeas pluríparas (Fonseca, 2002). 


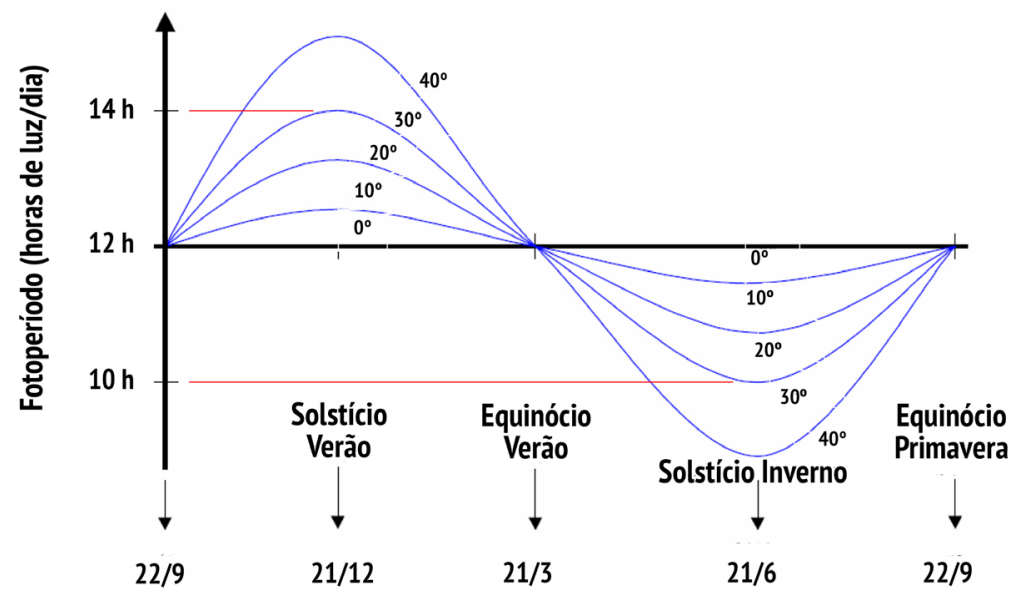

Figura 2 - Variação estacional do fotoperíodo em diferentes latitudes do Hemisfério Sul.

Nota: Adaptado de Bergamaschi (2009).

\section{Índices reprodutivos}

Os índices reprodutivos referem-se aos indicadores de eficiência reprodutiva e de acompanhamento do rebanho. Os principais são:

- Peso e idade à puberdade: medido em meses, retrata a idade e/ou peso em que o animal apresentou o primeiro estro com ovulação ou, ainda, idade em que o animal atingiu peso compatível com a reprodução (60 - 70\% peso de fêmea adulta).

- Período de serviço: intervalo do parto ao primeiro acasalamento fértil.

- Taxa de concepção: reporta o percentual de fêmeas gestantes após acasalamento, por monta natural ou inseminação artificial em um único ciclo.

- Fertilidade: reporta o percentual de fêmeas gestantes do total de fêmeas expostas a um período de acasalamento (estação de monta), podendo compreender vários ciclos.

- Intervalo de partos: intervalo em meses de um parto ao outro subsequente.

- Taxa de parição: percentual de fêmeas que pariram do total de animais expostos ao acasalamento.

- Perda fetal: percentual de animais que não pariram após terem sido diagnosticados gestantes.

- Período de gestação: intervalo em dias entre o acasalamento e o parto.

- Prolificidade: número de crias por parto.
Principais distúrbios reprodutivos na cabra leiteira

Entende-se como período improdutivo aquele em que a fêmea não esteja gestante, em lactação ou mesmo aquele no qual a produção de leite seja relativamente baixa (ex.: lactações avançadas).

A seguir são apresentados alguns conceitos básicos, os principais distúrbios reprodutivos e seus eventuais impactos na eficiência produtiva dos animais.

\section{Idade avançada ao primeiro parto}

A idade ao primeiro parto é um importante marcador da vida reprodutiva e produtiva das fêmeas. Cabras com idade relativamente longa ao primeiro parto podem indicar que passaram por problemas. 0 peso ideal para cobertura de cabritas corresponde a 60 - 70\% do peso de uma cabra adulta da mesma raça. Este peso pode ser alcançado mais precoce ou tardiamente, dependendo do sistema de produção ou mesmo da raça explorada (Figura 3). Em alguns criatórios, dependendo da estação do ano em que ocorreu o nascimento, as cabritas são acasaladas próximo ao peso e idade (8 meses) mínimos ou mesmo a uma idade pouco superior (12 meses) para que o primeiro acasalamento ocorra durante a estação de acasalamento natural. 


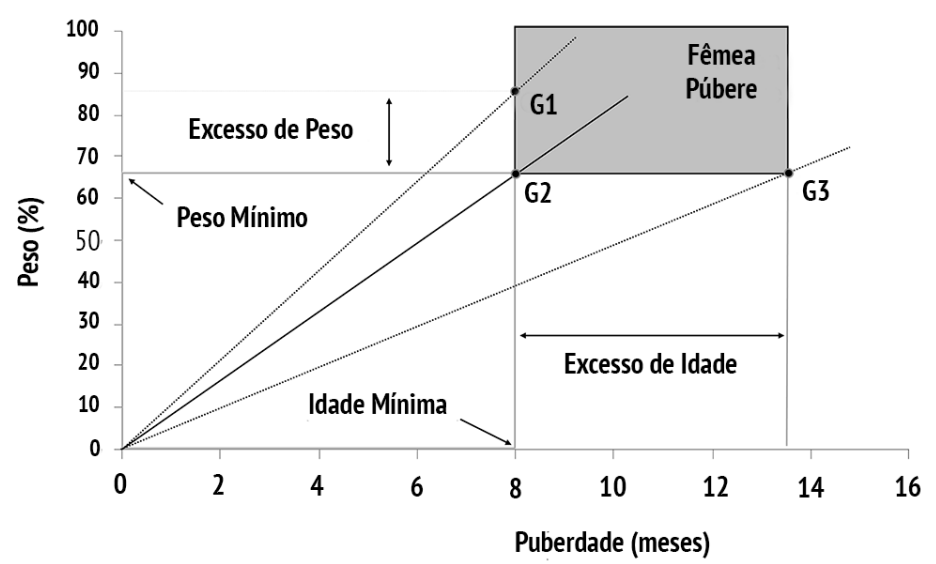

Figura 3 - Relação do percentual de peso corporal referente a uma fêmea adulta da raça e idade à puberdade em cabras e ovelhas em três diferentes sistemas de ganho de peso.

Nota: Adaptado de Fonseca e Bruschi (2008).
Em alguns criatórios, cabritas nascidas no primeiro semestre do ano são submetidas à indução de estro para serem acasaladas por volta dos oito meses de idade, respeitando o peso mínimo, procedimento realizado durante a estação de anestro.

Alguns distúrbios reprodutivos podem comprometer a fertilidade destes primeiros ciclos reprodutivos e, assim, elevarem o período improdutivo de fêmeas jovens, ou seja, o período entre o nascimento e a primeira gestação.

\section{Ninfomania}

A ninfomania é uma condição ainda pouco compreendida e está associada à apresentação de estro de forma prolongada na fêmea, sem a ocorrência de ovulação (Simões e Mascarenhas, 2008). Esta não é uma patologia propriamente dita, mas, sim, um sintoma que indica a presença de alguma alteração na fêmea, que deve ser investigada.

Em caprinos, a exemplo do que ocorre em outras espécies de ruminantes, a ninfomania está geralmente relacionada à doença cística ovariana. 0 cisto folicular ovariano produz estrogênio, o que resulta num ciclo estral curto de 3 a 7 dias ou ainda estro contínuo. Eventualmente, os efeitos estrogênicos levam ao relaxamento dos ligamentos pélvicos e as cabras demonstram comportamento similar a um macho. 0 diagnóstico pode ser confirmado por ultrassonografia. Normalmente, o sucesso será maior quando o tratamento for iniciado mais precocemente. Comumente, são utilizados 1.000 UI de gonadotrofina coriônica humana (hCG), $0,020 \mathrm{mg}$ de buserelina ou $0,5 \mathrm{mg}$ de gonadorelina (Medan et al., 2004; Simões e Mascarenhas, 2008; Matthews, 2016).

A ninfomania seguida de comportamento masculino pode ocorrer em alguns casos de neoplasias. Tumores ovarianos são raros em caprinos. Quando presentes, os tumores de células de granulosa são os mais comuns, sendo esta uma neoplasia ativa em produção de esteroides. 0 diagnóstico é feito por meio de ultrassonografia transretal ou transabdominal. A ovariectomia unilateral pode ser uma alternativa, caso a cabra possua grande valor genético e/ou econômico (Matthews, 2016).

Em bovinos, foi descrito que o estresse térmico em função da temperatura ambiente pode de forma indireta levar à ocorrência de ninfomania (Rocha et al., 2012). Apesar do mecanismo endócrino ser bastante similar entre as espécies, não foram encontrados relatos em caprinos de ninfomania associada ao estresse térmico.

\section{Cistos foliculares}

A doença cística ovariana é considerada uma das principais causas de infertilidade em rebanhos caprinos, e a incidência de cistos ovarianos em pesquisas utilizando ovários de abatedouro foi de 
12\% (Moreira et al., 1991). Dos cistos ovarianos já reportados em caprinos, o cisto folicular é o mais comum. Este cisto é diagnosticado quando há presença de uma estrutura anecoica, maior de 10 mm de diâmetro (Figura 4), na ausência de um corpo lúteo em três exames ultrassonográficos realizados a cada cinco dias (Medan et al., 2004). Desta forma, atualmente a ultrassonografia é o exame de eleição para diagnóstico da enfermidade, apesar de análises hormonais (estradiol e progesterona) poderem ser utilizadas como estratégias complementares.

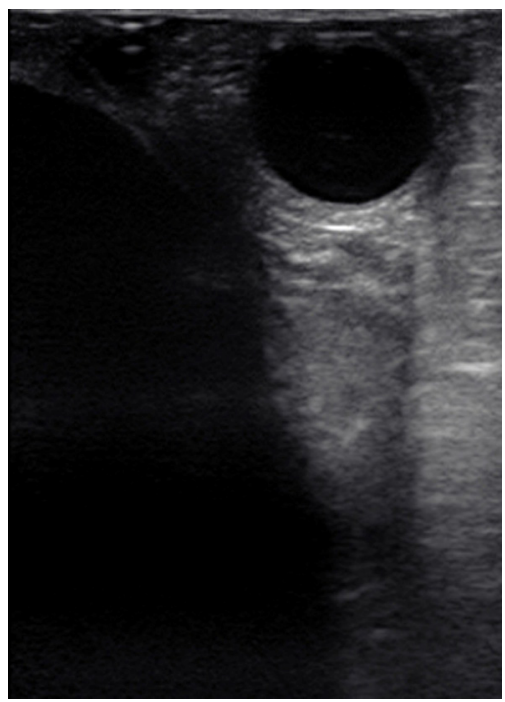

Foto: por Ana Lucia Maia.

Figura 4 - Imagem ultrassonográfica de cisto folicular em cabra, contendo estrutura anecóica superior a $10 \mathrm{~mm}$ de diâmetro.

O cisto folicular ovariano comumente produz estrogênio, o que resulta em ninfomania, como descrito anteriormente. Entretanto, já foi relatado em bovinos que este cisto pode ainda produzir progesterona, levando esta fêmea ao anestro, ou andrógenos, levando a um comportamento de virilismo (Nascimento e Santos, 2011).

A etiologia dos cistos ovarianos ainda não está esclarecida. Aparentemente, a liberação inapropriada de GnRH e/ou LH está associada à patogênese da enfermidade (Nascimento e Santos, 2011). Sendo assim, o tratamento do cisto folicular pode ser efetuado eficientemente com a administração de 10,5 $\mu \mathrm{g}$ de buserelina (GnRH sintético), seguido de $125 \mu \mathrm{g}$ de cloprostenol (análogo sintético da prostaglandina F2alfa), dez dias após a aplicação do GnRH (Medan et al., 2004). Curiosamente, nosso grupo relatou pela primeira vez a ocorrência de cistos foliculares associados à presença de hidrometra em cabras leiteiras, afecção que será descrita com mais detalhes posteriormente (Souza et al., 2013).

A presença de cistos foliculares tem sido descrita ao redor do mundo com variações em sua ocorrência. Balaro et al. (2016) relataram uma frequência de 0,9\% (15/1747) de cistos foliculares em ovelhas e cabras no estado do Rio de Janeiro e Zona da Mata Mineira. Jáa frequência de cistos foliculares em cabras na Índia tem tido pouca variação regional, entre 0,6 (6/1024) a 0,5\% (3/660) (Archana et al., 2013; Pawaiya et al., 2015). Como normalmente os cistos foliculares estão associados à falha gestacional, suas implicações negativas sobre a eficiência reprodutiva dependerão do período em que a patologia persistir no animal. A identificação ultrassonográfica e tratamento diminuirão este impacto quanto mais precoce a patologia for diagnosticada.

\section{Falha Luteal}

A função anormal do corpo lúteo afeta diretamente o desempenho reprodutivo da cabra (Rodriguez etal., 2015), sendo associada a desordens do ciclo ovariano e impossibilitando a ocorrência de gestação. A falha luteal mais comumente descrita é a regressão prematura do corpo lúteo (RPCL), que se caracteriza pela ocorrência da luteólise antes do período fisiológico em que o endométrio inicia a secreção pulsátil de prostaglandina F2 $\alpha$ (i.e., final da fase de diestro). A perda da funcionalidade do corpo lúteo pode ser evidente de três a quatro dias após o início do estro (Saharrea et al., 1998), determinando o ciclo estral curto.

É naturalmente observada nos pequenos ruminantes entre os períodos de transição de condições de anestro para ciclicidade, como na puberdade, no pós-parto precoce e no pós-anestro estacional (Christensen et al., 2014). Um fator relevante que se relaciona com a luteólise prematura é a superestimulação, tornando-se um importante obstáculo na produção in vivo de embriões de caprinos. 
Uma série de possíveis causas da RPCL são apontadas na literatura, como: falhas na préexposição de progesterona (Cognie et al., 1982); suporte gonadotrófico inadequado durante $\mathrm{o}$ desenvolvimento folicular ou a fase luteal inicial (Braden et al., 1989); secreção pré-ovulatória inadequada de estrógeno (Lamming e Mann, 1995); maturação inadequada do folículo préovulatório no momento do pico de LH, que ocasiona o desenvolvimento de corpo lúteo anormal (Stubbings et al., 1986); inadequado pico préovulatório de LH (baixa amplitude); ovulação de folículo de menor diâmetro (Sá Filho e Vasconcelos, 2008); elevadas concentrações de estradiol durante a fase luteal inicial (Saharrea et al., 1998) em virtude da presença de folículos persistentes, devido à superestimulação (Okada et al., 2000); inabilidade do corpo lúteo em responder às gonadotrofinas (Braden et al., 1989); estímulo luteolítico precoce (Chemineau et al., 1993); e maior sensibilidade do corpo lúteo a substâncias luteolíticas (Braden et al., 1989). Em virtude das inúmeras possibilidades de causas da regressão prematura do corpo lúteo, observa-se dificuldade na elaboração de um método preventivo eficiente.

O diagnóstico pode ser realizado pela observação do retorno ao estro em um curto intervalo desde o estro anterior (i.e., curta duração do ciclo estral). Em animais submetidos a procedimentos de laparoscopia ou laparotomia para a colheita ou inovulação de embriões, é possível observar que estruturas lúteas regredidas prematuramente apresentam-se pouco vascularizadas. Possivelmente esta alteração seja determinante para a realização de diagnóstico via ultrassonografia Doppler colorido, entretanto, a confirmação da eficiência desta técnica diagnóstica ainda permanece em pleito.

A RPCL que termina em um ciclo curto é a principal causa de falha gestacional no início da estação reprodutiva. Isto pode causar a perda do acasalamento. 0 ciclo curto implicará em aumento dos dias abertos para que o animal fique gestante. No caso da inseminação artificial, o custo da dose de sêmen é incorporado ao prejuízo econômico. 0 ciclo curto responde, portanto, por falhas em protocolos de controle do ciclo estral e gestacionais (Fonseca et al., 2012). Uma alternativa para minimizar seus efeitos negativos é não utilizar o primeiro estro da estação reprodutiva (Fonseca et al., 2007) ou ainda protocolos que controlam seu efeito negativo (Maia et al., 2017a).

\section{Perdas gestacionais}

As perdas gestacionais podem ser divididas em mortalidade embrionária e mortalidade fetal. Como parte do processo reprodutivo, um pequeno percentual de perdas deve ser considerado normal para que sejam eliminados genótipos indesejáveis (Jainudeen e Hafez, 2004). No entanto, quando em número elevado, tornam-se um dos principais fatores que afetam a eficiência econômica dos rebanhos voltados para produção (Diskin e Morris, 2008).

A morte embrionária precoce ocorre antes do reconhecimento materno da gestação e não influencia na duração do ciclo, muitas vezes não sendo notada. A morte embrionária tardia, embora numericamente inferior, gera um aumento na duração do ciclo e pode comprometer a produção da fêmea, no caso da impossibilidade de um novo acasalamento como ocorre em espécies que apresentam estacionalidade reprodutiva (Jainudeen e Hafez, 2004; Diskin e Morris, 2008). Desta forma, na pecuária leiteira, as perdas econômicas devido à morte do embrião são relevantes, visto que não estão ligadas somente à perda da cria, necessária para reposição e melhoramento genético do rebanho, mas também ao período em que a fêmea estará improdutiva (Engeland et al, 1999; Jonker, 2004). A morte fetal pode evoluir para o abortamento com a expulsão do concepto, ou retenção do mesmo, como nos casos de maceração ou mumificação do feto devido à presença ou ausência de microrganismos, respectivamente (Santa Rosa, 1966).

Em alguns casos, verifica-se ainda o desenvolvimento de hidrometra, devido à permanência do feto no útero materno, associada à persistência do corpo lúteo (Humblot et al., 1995, Brice et al., 2003). Ao exame ultrassonográfico (Figura 5), nota-se a presença de líquido (anecóico) contendo material disperso e móvel, que pode apresentar diferentes ecogenicidades (hipo a hiperecoico).

Na espécie caprina, fatores endócrinos, condições de trauma, estresse, idade, hierarquia social (fêmeas subordinadas), número de fetos, uso inadequado 
de medicamentos, manejo nutricional deficiente e plantas tóxicas estão relacionados à perda da cria (Engeland et al., 1997; Mobini et al., 2004; Matthews, 2016). Não obstante, agentes infecciosos (microrganismos) ou suas toxinas podem levar à alteração no desenvolvimento do feto de forma direta ou indireta pela ocorrência de placentite (Mobini et al., 2004; Givens e Marley, 2008). Em surtos de abortamentos, responsáveis por grandes perdas econômicas, sugere-se a investigação de doenças como toxoplasmose, neosporose, clamidiose, brucelose, leptospirose, listeriose, micoplasmose e salmonelose (Mobini et al. 2004; Givens e Marley, 2008; Martins et al., 2012).

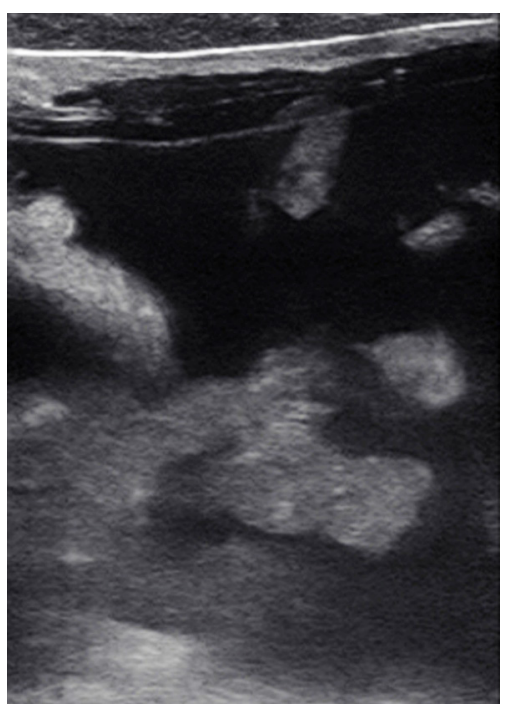

Foto: Ana Lucia Maia.

Figura 5 - Imagem ultrassonográica de morte fetal em cabra, caracterizada pela presença de material disperso (hipoecóico) no útero repleto de líquido (anecóico).

0 prejuízo econômico gerado pela perda gestacional dependerá da fase em que esta ocorre. No caso da morte embrionária precoce com retorno à ciclicidade, não haverá alteração na produtividade da fêmea. No entanto, a morte do embrião de forma tardia, quando seguida por um período de anestro estacional, representará a necessidade de indução de estro para novo acasalamento. Em cabras voltadas para a produção de leite, este atraso na gestação levará a uma fase improdutiva superior a um ano, se levados em consideração os cinco meses de gestação.

Nos casos de morte fetal seguida de expulsão ou retenção do concepto, existe a possibilidade de ocorrência de sequelas, que muitas vezes levam ao descarte da fêmea. Surtos de abortamentos devido a doenças infecciosas ou manejo nutricional inadequado geralmente trazem um impacto enorme no rebanho por atingirem vários animais ao mesmo tempo. Além da subsequente pausa na produção, o gasto com medicamentos agrava ainda mais a situação.

\section{Hidrossalpinge}

A tuba uterina é um órgão par, tubular, fino e tortuoso, que além de conectar o ovário ao útero, participa dos primeiros eventos reprodutivos, tais como: transporte e capacitação espermática, captação e maturação oocitária, fertilização e clivagens inicias do embrião (Ellington, 1991). A hidrossalpinge caracteriza-se pela distensão do lúmen da tuba devido ao acúmulo de líquido, como consequência de má formação congênita ou, mais frequentemente, da existência de uma obstrução (McEntee, 1990). De acordo com Nascimento e Santos (2011), as lesões que ocorrem neste órgão podem ser causadas por distúrbios que tiveram início nos ovários e/ou útero. Por ser uma estrutura estreita, em casos de edema, inflamação e cicatrização, a função da tuba uterina é rapidamente comprometida (Grunert et al. 2005).

Geralmente identificada após o abate, essa é uma enfermidade que pode comprometer parcial ou completamente a fertilidade da fêmea, dependendo da sua ocorrência uni ou bilateral, respectivamente (Arthur et al., 1983; Purohit, 2014). Considerada como uma condição de baixa frequência na espécie caprina (Santa Rosa, 1996), ao exame ultrassonográfico, a hidrossalpinge costuma ser confundida com hidrometra ou cisto folicular (Janet et al. 2001; Dawood, 2010). Todavia, a visualização de uma imagem ultrassonográfica contendo cortes do corno uterino lateral ou superior a uma estrutura circular (única) anecóica com diâmetro superior a $24 \mathrm{~mm}$, como verificado na Figura 6, sugere a presença de hidrossalpinge. 


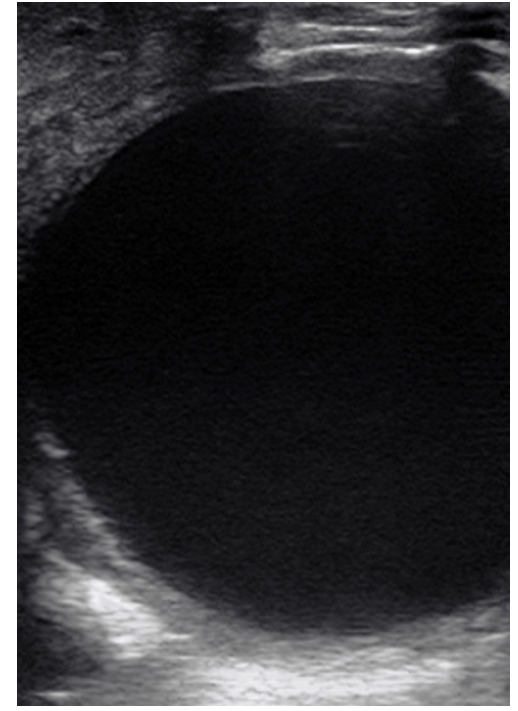

Foto: Ana Lucia Maia.

Figura 6 - Imagem ultrassonográfica de hidrossalpinge em cabra, contendo grande estrutura circular preenchida por líquido (anecóico), lateral ao corno uterino de aspecto hipoecóico (seta)..

Diferentemente da hidrometra, cabras com hidrossalpinge apresentam estro, são acasaladas, mas na maioria das vezes não apresentam a efetivação do parto. Caso seja feito um diagnóstico ultrassonográfico da hidrossalpinge, indica-se a avaliação do histórico reprodutivo da fêmea para que seja recomendado o descarte. Em caso de hidrossalpinge bilateral (infertilidade), quanto mais cedo for realizada esta verificação, menor será o gasto com o animal. No entanto, esse diagnóstico costuma ser dado próximo dos dois anos de idade, após uma ou mais estações de acasalamento e ausência de gestação.

Os custos aproximados com uma cabra até um ano de idade, período em que já se pode comparar o diagnóstico ultrassonográfico e histórico reprodutivo, são de R\$1.080. Este custo pode ser ainda maior se considerado o que ela deixa de produzir (crias e leite). Em criatórios que não possuem acompanhamento zootécnico e que não realizam exames ultrassonográficos, cabras com dois anos de idade e inférteis já apresentaram um custo de $\mathrm{R} \$$ 2.190 ao produtor, que geralmente continua insistindo na tentativa de manter a fêmea no rebanho devido a sua aparência saudável e robusta.

\section{Hidrometra}

A hidrometra ou pseudogestação é uma condição patológica do útero associada à persistência de corpo lúteo. Dentre as características da enfermidade estão o aumento do volume uterino, devido ao acúmulo de fluído asséptico, podendo levar à distensão abdominal, semelhante à gestação (Pietersen e Taverne, 1986; Santa Rosa, 1996). Em alguns casos, verifica-se a expulsão espontânea de grande volume de líquido ("cloudburst"), sem que sejam encontrados fetos e/ou restos placentários (Pietersen e Taverne, 1986; Duquesnel et al., 1992). Alguns produtores relatam a diminuição na produção de leite (Wittek et al., 1998) ou, de forma contrária, o desenvolvimento do úbere e lactogênese em fêmeas não lactantes (Taverne et al., 1995).

Vários fatores já foram relacionados à pseudogestação. Segundo Nascimento e Santos (2011), algumas causas anatômicas como obstrução do canal cervical ou vaginal, presença de cisto folicular e hiperestrogenismo, acompanhados de ninfomania de longa duração e persistência do hímen, podem estar ligadas à ocorrência de mucometra e hidrometra. Muitos pesquisadores relataram que a hidrometra ocorre na maioria das vezes em cabras adultas e que raramente afeta fêmeas nulíparas a partir de seis meses (Mialot 1991; Duquesnel et al., 1992; Hesselink, 1993a; Wittek et al., 1998). Taverne et al. (1995) acreditam que distúrbios entre os mecanismos luteolíticos e luteotróficos durante o ciclo ovariano possam apresentar um importante papel na etiologia da hidrometra.

A sincronização e indução de estro com progestágenos também são citadas como possíveis causas da enfermidade (Duquesnel et al.,1992; Hesselink, 1994; Humblot et al., 1995). Todavia, cabras com estro induzido por programa de luz artificial ou mesmo sem nenhuma forma de indução de estro podem apresentar hidrometra (Maia et al., 2017b). De acordo com Matthews (2016), o prolongamento da lactação pode estar ligado à permanência do corpo lúteo após um ciclo estral em que não houve gestação, sendo particularmente comum em fêmeas durante o segundo ano seguido de lactação sem serem acasaladas. Não obstante, Brice et al. (2003) destacam duas principais 
possibilidades: a persistência do corpo lúteo cíclico na ausência de fecundação e a manutenção do corpo lúteo após início de gestação seguido de mortalidade embrionária.

Geralmente, a hidrometra é identificada por exame ultrassonográfico durante diagnóstico de gestação após a estação de acasalamento. No entanto, a enfermidade também ocorre em fêmeas que se apresentam em anestro e não foram acasaladas (Taverne et al., 1995), sendo recomendada a avaliação ultrassonográfica total do rebanho. Cabras submetidas à indução de estro no período de anestro estacional podem desenvolver hidrometra após o parto e retorno à ciclicidade durante a estação natural de acasalamento (East, 2007). A imagem ultrassonográfica da hidrometra apresenta grandes compartimentos repletos de líquido (anecoico), separados por finas paredes (hiperecoico) (Pietersen e Taverne, 1986), conforme a Figura 7.

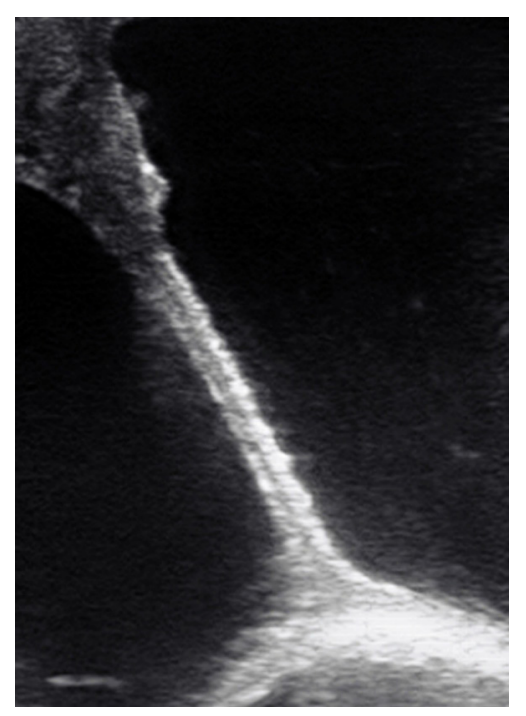

Foto: Ana Lucia Maia.

Figura 7 - Imagem ultrassonográfica de hidrometra em cabra, caracterizada por segmentos repletos de líquido (anecoico) separados por fina parede uterina (hiperecoico).

O tratamento com uma ou duas aplicações de prostaglandina foi avaliado por vários pesquisadores, obtendo a drenagem total ou parcial do útero (Pietersen and Taverne 1986; Hesselink, 1993b; Batista et al., 2001; Moraes et al., 2007; Souza et al., 2013). Verificada com maior frequência em cabras voltadas à produção leiteira, a hidrometra é sem dúvida uma das maiores causas de perda econômica neste segmento. Embora não seja um risco para a saúde das cabras, a pseudogestação anula a capacidade reprodutiva da fêmea, gerando prejuízo para o produtor, uma vez que os filhotes esperados não vão nascer e a produção de leite será reduzida (Hesselink, 1993a, Martel, 2001).

Sem a realização de exames ultrassonográficos de rotina no rebanho, cabras com hidrometra são identificadas em torno de seis meses após a estação de acasalamento, quando as outras fêmeas do rebanho já tiveram suas crias e iniciaram a produção de leite. Em cabras que não foram acasaladas por não apresentarem estro e que não apresentam uma distensão abdominal, o diagnóstico tornase ainda mais difícil. 0 gasto equivalente ao período de "gestação" (cinco meses) de uma cabra com hidrometra é de $\mathrm{R} \$ 450$. Caso a verificação da enfermidade ocorra durante a estação de acasalamento e o tratamento seja realizado antes do início do período de anestro, serão gastos, no mínimo, mais $R \$ 450$ para que essa fêmea retorne à produção de leite. No entanto, se a identificação da enfermidade ocorrer durante o anestro estacional, será necessária a realização do tratamento seguido de indução de estro ou a espera pelo início da estação reprodutiva. 0 período em que uma única cabra do rebanho fica improdutiva pode ultrapassar um ano, quando levamos em consideração os cinco meses de gestação (em caso de sucesso do tratamento).

\section{Considerações finais}

Para alcançar um aumento na eficiência reprodutiva do rebanho, considerada como fator limitante do desenvolvimento da caprinocultura, alguns fatores devem ser considerados: preocupação com o ambiente e o bem-estar animal; manejo nutricional elaborado de acordo com as exigências de cada categoria; tecnologias reprodutivas utilizadas de forma adequada e eficiente; e planejamento sanitário conduzido de forma profilática. Ressalta-se, ainda, a importância da realização de exames ultrassonográficos de 
forma constante, associados ao controle zootécnico dos animais. De acordo com essas informações, o produtor e/ou o técnico podem identificar alguns distúrbios reprodutivos que estejam influenciando de forma negativa os índices zootécnicos do rebanho, fatores fundamentais para alcançar a produtividade e lucratividade da criação de cabras.

\section{Agradecimentos}

Os autores agradecem à Empresa Brasileira de Pesquisa Agropecuária (EMBRAPA; Projeto 02.08.02.005.00.04), à Fundação de Amparo à Pesquisa do Estado de Minas Gerais (FAPEMIG; Projeto CVZ - PPM 00201-17) e ao Conselho Nacional de Desenvolvimento Científico e Tecnológico (CNPq; Projeto 479826/2013-7) pelo suporte financeiro que resultou em importantes resultados e no conteúdo desta revisão. Ana Lucia Rosa e Silva Maia é bolsista nota 10 FAPERJ. Joanna Maria Gonçalves Souza-Fabjan é bolsista da CAPES. Maria Emília Franco Oliveira e Felipe Zandonadi Brandão são bolsistas do CNPq.

\section{Referências}

Archana S, Vijay M, Anita B, Indu, V. Pathological study on Occurrence of various reproductive diseases in goats at Rajasthan. J Immunol Immunopathol. 2013;15(1):197-201.

Arthur GH, Noakes DE, Pearson H. Veterinary reproduction and obstetrics. 6th ed. London: Bailliere Tindall; 1983. 641p.

Balaro MFA. Fisiologia reprodutiva em cabras da raça Saanen em clima tropical: dinâmica luteal, estacionalidade reprodutiva e potencial da resposta superovulatória [tese]. Niterói: Universidade Federal Fluminense; 2016.

Balaro MFA, Maia ALRS, Ribeiro ACS, Santos AS, Moura LFGM, Fonseca JF, et al. Ultrasound findings of common pathologies of the female genital system of small ruminants. The 29th World Buiatrics Congress; 2016; Dublin, IE. Dublin: Veterinary Ireland; 2016; p.155.

Batista M, Medina J, Calero R, Gonzalez F, Quesada E,
Gracia A. Incidence and treatment of hydrometra in Canary Island goats. Vet Rec. 2001;149(11):329-30.

Bergamaschi H. Fotoperiodismo. 2009 [acesso 23 jun. 2009]. Disponível em: https://tinyurl.com/ycbxdyxa.

Braden TD, Sawyer HR, Niswender GD. Functional and morphological characteristics of the first corpus luteum formed after parturition in ewes. J Reprod Fertil. 1989;86(2):525-33.

Brice G, Leboeuf B, Broqua C. La pseudogestation chez la chèvre laitière. Point Vét. 2003;(237):50-2.

Chemineau P, Daveau A, Locatelli A, Maurice F. Raminduced short luteal phases-effects of hysterectomy and cellular composition of the corpus luteum. Reprod Nutr Dev. 1993;33(3):253-61.

Christensen ACM, Haresign W, Khalid M. Progesterone exposure of seasonally anoestrous ewes alters the expression of angiogenic growth factors in preovulatory follicles. Theriogenology. 2014;81(2):358-67.

Cognie Y, Gray SJ, Lindsay DR, Oldham CM, Pearce DT, Signoret JP. A new approach to controlled breeding in sheep using the ram effect. Proc Aust Soc Anim Prod. 1982;14:519-22.

Corteel JM, Leboeuf B, Baril G. Artificial breeding of adult goats and kids induced with hormones to ovulate outside the breeding season. Small Rumin Res. 1988;1(1):19-35.

Dawood KE. Hydrosalpinx and hydrobursitis in infertile goats. Turk J Vet Anim Sci. 2010;34(5):477-80.

Deshpande D, Ravindra JP, Narendranath R, Narayana K. Ovarian antral follicular dynamics and serum progesterone concentration during the oestrous cycle of Bannur ewes. Indian J Anim Sci. 1999;69(11):932-4.

Diskin MG, Morris DG. Embryonic and early foetal losses in cattle and other ruminants. Reprod Domest Anim. 2008;43 Suppl 2:260-7.

Duquesnel R, Parisot D, Pirot G, Mialot JP, Saboureau L, Étienne $\mathrm{P}$, et al. La pseudogestation chez la chèvre. Ann Zootech. 1992;41:407-15. 
East NE. Reproductive Health Program. In: Youngquist RS, Threlfall WR (EE.). Current Therapy in Large Animal Theriogenology. $2^{\circ}$ ed. St. Louis: Saunders Company; 2007. p. 558-9.

Ellington JE. The bovine oviduct and its role in reproduction: a review of the literature. Cornell Vet. 1991;81(3):313-28.

Engeland IV, Ropstad E, Kindahl H, Andresen O, Waldeland $\mathrm{H}$, Tverdal A. Foetal loss in dairy goats: function of the adrenal glands, corpus luteum and the foetal - placental unit. Anim Reprod Sci. 1999;55(3-4):205-22.

Engeland IV, Waldeland H, Andresen O, Tverdal A. Foetal loss in dairy goats: an epidemiological study in 515 individual goats. Anim Reprod Sci. 1997;49(1):45-53.

Evans ACO. Ovarian follicle growth and consequences for fertility in sheep. Anim Reprod Sci. 2003;78(3-4):289-306.

Fonseca JF, Maffili VV, Santos ADF, Fürst R, Prosperi CP, Rovay $\mathrm{H}$, et al. Effects of prostaglandin administration 10 days apart on reproductive parameters of cyclic dairy nulliparous goats. Arq Bras Med Vet Zootec. 2012;64(2):349-58.

Fonseca JF, Bruschi JH. Produção de caprinos e ovinos em Minas Gerais. In: Diniz FH, Ferreira JR, Souza AD, Albuquerque LC, Fagundes RBS (EE.). Sustentabilidade da produção de leite na agricultura familiar. Juiz de Fora: Embrapa Gado de Leite; 2008.

Fonseca JF, Cruz RC, Pinto PHN, Facó O. Inseminação Artificial em Pequenos Ruminantes. I Workshop de Ciência Animal da Bahia; 20-22 out. 2010; Ilhéus, BA. Ilhéus: UESC; 2010. 30 p.

Fonseca JF, Souza JMG, Bruschi JH. Sincronização de estro e superovulação em ovinos e caprinos. II Simpósio de Caprinos e Ovinos da EV-UFMG; 2007; Belo Horizonte. Belo Horizonte: CENEx - EV/UFMG; 2007. p. 167-95.

Fonseca JF, Souza JMG, Bruschi, J.H. Considerações sobre eficiência reprodutiva no sistema de produção. V Simpósio Mineiro de Ovinocultura; 20-21 ago. 2009; Lavras, MG. Lavras: Universidade Federal de Lavras; 2009. p. 152-80.
Fonseca JF. Controle e perfil hormonal do ciclo estral e performance reprodutiva de cabras Alpinas e Saanen [tese]. Viçosa, MG: Universidade Federal de Viçosa; 2002.

Ginther OJ, Kot K. Follicular dynamics during the ovulatory season in goats. Theriogenology. 1994;42(6):987-1001.

Givens MD, Marley MSD. Infections causes of embryonic and fetal mortality. Theriogenology. 2008;70(3):270-85.

Gordon I. Controlled reproduction in sheep and goats. Cambridge, UK: University Press; 1997. 62 p.

Grunert E, Birgel EH, Vale WG. Patologia e Clínica da Reprodução dos Animais Mamíferos Domésticos: Ginecologia. São Paulo: Livraria Varela; 2005. 551 p.

Hesselink JW, Taverne MA. Ultrasonography of the uterus of the goat. Vet Q. 1994;16(1):41-5.

Hesselink JW. Hydrometra in dairy goats: reproductive performance after treatment with prostaglandins. Vet Rec. 1993a;133(8):186-7.

Hesselink JW. Incidence of hydrometra in dairy goats. Vet Rec. 1993b;132(5):110-2.

Humblot P, Brice G, Chemineau P, Broqua B. Mortalité embryonnaire chez la chèvre laitière après synchronisation des chaleurs et insémination artifielle à contre saison. II Rencontres Recherches Ruminants; 13-14 dez. 1995; Paris. Paris: Institute National de la Recherche Agonomique (INRA); 1995. p. 387-9.

Jainudeen MR, Hafez ESE. Falha Reprodutiva em Fêmeas. In: Hafez ESE, Hafez B. Reprodução Animal. $7^{\circ}$ ed. São Paulo: Editora Manole; 2004. p. 260-89.

Janett F, Lischer C, Grest P. Hydrosalpinx bei der Ziege. Schweiz Arch Tierheilkd. 2001;143(2):105-8.

Jonker FH. Fetal death: comparative aspects in large domestic animals. Anim Reprod Sci. 2004;82-83:415-30.

Lamming GE, Mann GE. Control of endometrial oxytocin receptors and prostaglandin F2 alpha production in cows by progesterone and oestradiol. J Reprod Fertil. 1995;103(1):69-73. 
Martel JLM. Incidencia de la hidrómetra en la agrupación caprina Canaria. Vector Plus. 2001;6(18):28-34.

Martins EC. Caprinocultura brasileira: as evidências do censo agropecuário 2006 [acesso 18 mar. 2010]. Disponível em: https://tinyurl.com/y9gxsrm9.

Martins G, Brandão FZ, Hamond C, Medeiros M, Lilenbaum W. Diagnosis and control of an outbreak of leptospirosis in goats with reproductive failure. Vet J. 2012;193(2):600-1.

Matthews J. Diseases of the goat. $4^{\circ}$ ed. Hoboken, NJ: Wiley-Blackwell; 2016. 242 p.

Medan MS, Watanabe G, Sasaki K, Taya K. Transrectal ultrasonic diagnosis of ovarian follicular cysts in goats and treatment with GnRH. Domest Anim Endocrinol. 2004;27(2):115-24.

Mialot JP, Saboureau L, Guéraud JM, Prengere E, Parizot D, Pirot G, et al. La pseudogestation chez la chèvre: observations préliminaires. Recl Med Vet. 1991;167(3-4):383-90.

Mobini S, Heath AM, Pugh DG. Teriogenologia de Ovinos e Caprinos. In: Pugh DG. Clínica de Ovinos e Caprinos. $1^{\circ}$ ed. São Paulo: Editora Rocca; 2004. p. 145-208.

Moraes EPBX, Santos MHB, Arruda IJ, Bezerra FQG, Aguiar Filho CR, Neves JP, et al. Hydrometra and mucometra in goats diagnosed by ultrasound and treated with PGF2 $\alpha$. Med Vet. 2007;1(1):33-9.

Moreira ELT, Nascimento EFD, Chquiloff MAG, Dodascimento EF. Morphological alterations in the ovaries and uterus of Capra hircus. L1 regressive alterations. Arq Esc Med Vet Univ Fed Bahia. 1991;14:25-39.

Nascimento EF, Santos RL. Patologia da Reprodução dos Animais Domésticos. $3^{\circ}$ ed. Rio de Janeiro: Guanabara Koogan; 2011. 147 p.

Okada A, Kamada S, Jeon CW, Miyamoto A, Fukui Y. Incidence of abnormal corpus luteum in superovulated ewes. J Reprod Dev. 2000;46(6):397-402.

Pawaiya BVRVS, Shivasharanappa N, Gururaj K, Gupta,
Gangwar NK, Singh DD, et al. Occurrence of pathological conditions in the female genitalia of goats. Indian J Vet Pathol. 2015;39(3):197-201.

Pieterse MC, Taverne MAM. Hydrometra in goats: diagnosis with real-time ultrasound and treatment with prostaglandins or oxytocin. Theriogenology. 1986; 26(6):813-21.

Purohit GN. Ovarian and oviductal pathologies in the buffalo: Occurrence, diagnostic and therapeutic approaches. Asian Pac J Reprod. 2014;3(2):156-68.

Rodriguez MGK, Campanholi SP, Maciel GS, Oliveira MEF. Regressão luteal prematura em pequenos ruminantes. Rev Bras Reprod Anim. 2015;39(2);270-6.

Sá Filho OG, Vasconcelos JLM. Regressão prematura do corpo lúteo em bovinos. Vet e Zootec. 2008;15:220-33.

Saharrea A, Valencia J, Balcázar A, Mejía O, Cerbón JL, Caballero V, et al. Premature luteal regression in goats superovulated with PMSG: effect of hCG or GnRH administration during the early luteal phase. Theriogenology. 1998;50(7):1039-52.

Santa Rosa J. Enfermidades em caprinos: diagnóstico, patogenia, terapêutica e controle. Brasília: Embrapa-SPI; Sobral: Embrapa-CNPC; 1996. 220 p.

Simões J, Mascarenhas R. Caracterização de quistos foliculares ováricos em cabras multíparas da raça Serrana. Pubvet. 2008;2(15):1-11.

Souza JMG, Maia ALRS, Brandão FZ, Vilela CG, Oba E, Bruschi JH, et al. Hormonal treatment of dairy goats affected by hydrometra associated or not with ovarian follicular cyst. Small Rumin Res. 2013;111(1-3):104-9.

Stubbings RB, Bosu WTR, Baker CA, King GJ. Serum progesterone concentrations associated with superovulation and premature corpus luteum failure in dairy goats. Can J Vet Res. 1986;50(3):369-73.

Taverne MAM, Hesselink JW, Bevers MM, Van Oord HA, Kornalijnslijper JE. Aetiology and endocrinology of pseudopregnancy in the goat. Reprod Domest Anim. 1995;30(4):228-30. 
Wittek T, Erices J, Elze K. Histology of the endometrium, clinical-chemical parameters of the uterine fluid and blood plasma concentrations of progesterone estradiol $17 ß$ and prolactin during hydrometra in goats. Small Rumin Res. 1998;30:105-12. 